\title{
N-methyl-D-aspartate Receptor Antagonists may Ameliorate Spinal Cord Injury by Inhibiting Oxidative Stress: An Experimental Study in Rats
}

\author{
Guvenc DOGAN ${ }^{1}$, Onur KARACA ${ }^{2}$ \\ ${ }^{1}$ Hitit University, School of Medicine, Department of Anesthesiology and Reanimation, Corum, Turkey \\ ${ }^{2}$ Aksaray University, Faculty of Medicine, Department of Anesthesiology and Reanimation, Aksaray, Turkey
}

Corresponding author: Guvenc DOGAN guvencdogan@gmail.com

\section{ABSTRACT}

AIM: To investigate the neuroprotective effect of a N-methyl-D-aspartate (NMDA) receptor antagonist (amantadine) in an experimental spinal cord injury (SCl) model.

MATERIAL and METHODS: Thirty male Sprague-Dawley rats were divided into three groups: control (I), SCI (II), and SCl + amantadine (III). SCI was created using clip compression technique. At the end of day 7, blood samples were obtained from the rats and analyzed using various biochemical markers. Histological examination was also performed. MDA, GSH, and MPO assays were done. VEGF, TNF-a, and Baxexpressions were also analyzed.

RESULTS: The group III had several inflammatory cells in the gray and white matter, with mildly degenerated multipolar and bipolar cells. Some bipolar and multipolar neurons showed TNF-a expression; however, TNF-a was found to be weak in small groups of inflammatory cells around the blood vessels in the substantia grisea and alba. Positive Bax expression was observed in the substantia grisea layer, particularly in the membrane of some bipolar neurons and glial cells; however, negative Bax expression was observed in neuron and glial cells and showed positive VEGF expression in the vascular endothelium in the group III.

CONCLUSION: NMDA receptor antagonists, especially amantadine, may ameliorate SCI by inducing angiogenesis, affecting inflammation and apoptosis. It inhibits oxidative stress and the signaling pathways following $\mathrm{SCl}$ in rats.

KEYWORDS: Amantadine, Oxidative stress, Spinal cord injury, Rat, VEGF

\section{INTRODUCTION}

pinal cord injury (SCl) can have a traumatic and nonS traumatic origin and often results in catastrophic dysfunction and disability. The pathophysiological mechanisms underlying hypoxic/ischemic $\mathrm{SCl}$ remain unclear. The neurological damage during insult is termed "primary injury" Progressive tissue loss continues because of pathophysiological, hemodynamic, and biochemical mechanisms that occur within hours, days, or even weeks after the trauma and is termed secondary injury (22). Prior studies have demonstrated the detrimental nature of secondary tissue injury compared with the primary injury. Activated endogenic substrates, inflammation, and free radicals play a critical role in secondary damage $(4,9)$. Ischemic injury in neural tissue is aggravated by reperfusion resulting in lipid peroxidation, fiber degeneration, and progressive loss of motor neurons with a steady decline in motor function (6). Glutamate-mediated excitotoxicity, reactive oxygen species (ROS) formation, and lipid peroxidation contribute to neuronal dysfunction and cell loss after traumatic and ischemic injuries of the central nervous system (CNS). Both types of injuries have been shown to result in increased release of glutamate, sustained activation of glutamate receptors, and increased accumulation of calcium $\left(\mathrm{Ca}^{2+}\right)$. Direct evidence indicates that activation of glutamate receptors and the $\mathrm{Ca}^{2+}$ influx induces ROS, superoxide anion, and hydrogen peroxide formation (2). 
Dogan G. and Karaca O: Amantadine and Spinal Cord Injury

$\mathrm{N}$-methyl-D-aspartate (NMDA) receptor antagonists increase dopamine release, block dopamine reuptake, and inhibit microglial activation and neuroinflammation (17). Amantadine is a NMDA receptor antagonist and used in the treatment of L-DOPA-induced dyskinesia and psychiatric symptoms of Parkinson's disease (30). However, it has been proven to be beneficial in multiple sclerosis fatigue, major depressive disorder, traumatic brain injury, and refractory electrical status epilepticus (32).

No study has been performed regarding the effectiveness of amantadine in SCl. Hence, this study aimed to investigate the protective effect of NMDA receptor antagonist in SCl.

\section{MATERIAL and METHODS}

The investigation was conducted according to the Guide for the Care and Use of Laboratory Animals published by the US National Institutes of Health (NIH Publication no. 85-23, revised 1996). All techniques performed in this study were approved by the Ethics Committee for Animal Experimentation of University of Health Sciences, Ankara Education and Research Hospital, Turkey. Thirty male Sprague-Dawley rats $(250-280 \mathrm{~g})$ were placed under alternating light/dark cycles at $22 \pm 1^{\circ} \mathrm{C}$ for 12 hours with ad libitum access to standard pelleted nourishment and water. All 30 rats were divided into three groups: control group (group I), $\mathrm{SCl}$ group (group II), and $\mathrm{SCl}+$ amantadine group (group III). The rats of the control $(n=10)$ and $\mathrm{SCl}$ groups $(\mathrm{n}=10)$ were subcutaneously administered $1.5-\mathrm{ml}$ physiologic saline solution for 7 days.

\section{Spinal Cord Injury Model}

The experimental rats were anesthetized intraperitoneally with $50 \mathrm{mg} / \mathrm{kg}$ and $1 \mathrm{mg} / \mathrm{kg}$ of ketamine and chlorpromazine. Each rat was positioned on a heating pad in the prone position, and a rectal test was conducted. Under aseptic conditions, the spinous processes and laminar arcs of T5-12 were removed following a T5-12 midline skin incision and paravertebral muscle dissection. The relative angulation of the spinous processes of the T9, T10, and T11 vertebrae was considered to be the critical intraoperative landmark: T9 points caudally, T10 points dorsally, and T11 points rostrally. This angulation forms a "triangle" that helps to check whether the animal is positioned flat on the operating table. After the T11 and T12 vertebrae had been identified, a laminectomy was performed at T11 and T12 using Friedman-Pearson rongeurs. The clip was then held open with a clip utensil with the lower cutting edge of the clip passing extradurally around the spinal cord and nerve roots at the intersection of the T11 and T12 vertebrae compared with the L1-2 spinal cord segmental level. The clip was then quickly discharged from the tool to deliver a bilateral impact force and sustained dorsoventral compression. SCI with a moderate-to-severe was produced by clip compression method of Rivlin and Tator (27). The compression of the spinal cord was maintained for $60 \mathrm{sec}$ before removal of the clip. The muscles were then sutured using 3-0 polyglactin sutures, and the skin was closed with Michel clips (23). Following the surgical procedure, the rats were placed in a warming chamber, and their body temperatures were maintained at approximate- ly $37^{\circ} \mathrm{C}$ until they regained complete consciousness. The rats in the $\mathrm{SCl}$ group received only intraperitoneal saline injection an hour after SCl.

\section{Amantadine Administration}

Amantadinehydrochloride (Sigma A1260) was purchased from Sigma-Aldrich (Ankara, Turkey) and dissolved in sterile saline. After SCl, the rats of the group III received $45 \mathrm{mg} / \mathrm{kg}$ of intraperitoneal amantadine for 7 days. At the end of the seventh day, blood samples were obtained from the rats and analyzed using various biochemical markers. After 7 days, all animals were euthanized using an intraperitoneal injection of $5 \mathrm{mg} / \mathrm{kg}$ xylazine $\mathrm{HCl}$ (Rompun, Bayer HealthCare AG, Germany) and $50 \mathrm{mg} / \mathrm{kg}$ ketamine $\mathrm{HCl}$ (Ketalar, Pfizer Inc, USA). The medulla spinalis tissues were promptly removed. For the histological examination, the spinal cord was fixed in $10 \%$ formaldehyde solution, post-fixed in $70 \%$ alcohol, and embedded in paraffin wax. The sections were stained with hematoxylin-eosin.

\section{Malondialdehyde and Glutathione Assays}

Spinal cord tissue samples were homogenized in supercold $150-\mathrm{mM} \mathrm{KCl}$ to detect malondialdehyde (MDA) and glutathione (GSH) levels. MDA levels were examined for lipid peroxidation products, and the results were expressed as nmol MDA/g tissue (14). GSH levels were assessed using a spectrophotometric technique using Ellman's reagent, and the results were expressed as $\mu \mathrm{mol} \mathrm{GSH} / \mathrm{g}$ tissue (7).

\section{Measurement of Myeloperoxidase Activity}

Myeloperoxidase (MPO) activity levels were measured using the method described by Hillegass et al. (16). Spinal cord tissue specimens were homogenized in 50-mM potassium phosphate buffer (PB) at pH 6.0 and centrifuged at $41,400 \mathrm{~g}$ for 10 minutes. The pellets were then suspended in $50-\mathrm{mM}$ PB containing $0.5 \%$ hexadecyltrimethyl-ammonium bromide (HETAB). After three freeze-defrost cycles with sonication between cycles, the samples were centrifuged at 41,400 $\mathrm{g}$ for 10 minutes. Aliquots $(0.3 \mathrm{ml})$ were added to $2.3 \mathrm{ml}$ of the response mixture containing $50-\mathrm{mM} \mathrm{PB}$, o-dianisidine, and $20-\mathrm{mM} \mathrm{H}_{2} \mathrm{O}_{2}$ solution. One unit of enzyme activity was defined as the MPO level that caused an adjustment in absorbance, estimated at $460 \mathrm{~nm}$ for 3 minutes. MPO activity was expressed as $\mu / g$ tissue.

\section{Immunohistochemical Technique}

Formaldehyde-fixed tissue was embedded in paraffin wax for further immunohistochemical examination. Sections were deparaffinized in xylene and extracted in distilled water through a descending alcohol series. The antigen retrieval process was performed twice (at 7 minutes and 5 minutes, respectively) using EDTA buffer solution ( $\mathrm{pH} 6.0$ ) in a microwave oven at $700 \mathrm{~W}$. The sections were cooled to room temperature for 30 minutes and washed twice in distilled water for 5 minutes. Endogenous peroxidase activity was blocked in $0.1 \%$ hydrogen peroxide for 20 minutes. Ultra V block (Cat. No. 85-9043, Invitrogen, Carlsbad, California, USA) was applied for 10 minutes prior to the application of the primary antibodies: tumor necrosis factor-alpha (TNF-a; Cat. 
No. P300A, Invitrogen, Carlsbad, California, USA), vascular endothelial growth factor (VEGF) antibody (Cat. No. PA3067, Invitrogen, Carlsbad, California, USA), and Bax antibody (Cat. No. 33-6600, Invitrogen, Carlsbad, California, USA). A secondary antibody (Cat. No. 85-9043, Invitrogen, Carlsbad, California, USA) was applied for 20 minutes. Slides were then incubated in streptavidin-peroxidase for 20 minutes, and diaminobenzidine (DAB, Cat. No. 34002, Invitrogen, Carlsbad, California, USA) was used as the chromogen. Control slides were prepared using the same procedure, but phosphate buffered saline was used instead of the primary antibodies. After counterstaining with hematoxylin and washing in tap water for 8 minutes, sections were examined under a light microscope.

\section{Histologic Examinations}

The specimens obtained from the spinal cord were fixed with neutral buffered $10 \%$ formalin solution. Spinal cord specimens were directly dehydrated through an ascending alcohol series and embedded in paraffin wax. Sections of $5 \mu \mathrm{m}$ were cut using a microtome (Rotatory Microtome, Leica, RM 2265, Germany) and mounted on the smeared slides. The sections were stained with hematoxylin-eosin to delineate the white and gray matters.

\section{Statistical Analysis}

The number of groups (n), mean (mean), standard deviation (SD), median (median), $25^{\text {th }}$ percentile, and $75^{\text {th }}$ percentile were calculated. In addition, the Shapiro-Wilk normality test was used to determine whether the groups showed normal distribution. One-way analysis of variance was used to compare the groups. The difference between the groups was evaluated to be statistically significant at $p<0.05$. Different groups were compared using Bonferroni correction. Groups were shown as mean $\pm 2 S D$ graphically. For statistical analysis, SPSS (Version 22) package program was used.

\section{RESULTS}

In this study, the control (group I), SCI (Group II), and SCI + amantadine group (group III) were biochemically analyzed. MPO activity, known as an indicator of neutrophil infiltration, was substantially higher in the spinal cord tissues of the rats in the group II than in those of the rats in the control group $(p<0.001)$. The injury caused a significant increase in MDA levels $(p<0.001)$ with a corresponding decrease in $\mathrm{GSH}$ levels $(p<0.001)$. Amantadine treatment decreased MDA levels and MPO activity by day 7 (Table I).

On histological examination of the spinal cord sections of the group I, the nuclei of bipolar and multipolar-like neurons in the gray matter layer were observed to be rich in chromatin, and the nerve extensions were distributed in parallel. The glial cells with oval nuclei and their axonal and dendritic process in the white matter were elongated through the periphery of the synaptic structures (Figure 4A; hematoxylin-eosin stain, Bar: $100 \mu \mathrm{m})$. In the group II, degeneration and apoptotic changes in ependymal cells, mononuclear cell infiltration in the substantia grisea layer, dilation of the blood vessels, and hemorrhage were observed (Figure 4B; hematoxylin-eosin stain, Bar: $50 \mu \mathrm{m})$. On histopathological examination of the spinal cord sections of the group III, few inflammatory cells were observed in the gray and white matter. Mildly degenerated multipolar and bipolar cells and a few glial cells with pyknotic nuclei were observed. Synaptic extensions were observed to be parallel and prominent (Figure 4C; hematoxylin-eosin stain, Bar: $50 \mu \mathrm{m})$.

In group I, TNF-a activity was observed in the glial cells and unipolar neurons in the substantia grisea layer, whereas it was weak in the bipolar and multipolar neurons and synaptic areas (Figure 5A; TNF-a immunostaining, Bar: $100 \mu \mathrm{m}$ ). In the SCl group, TNF-a expression was significant in glial macrophages, dilated vascular endothelial cells, bipolar and multipolar neurons, and in the inflammatory cells around the small blood vessels (Figure 5B; TNF-a, immunostaining, Bar: $100 \mu \mathrm{m}$ ). In the group III, the glial cells and some bipolar and multipolar neurons showed TNF-a expression; however, TNF-a was found to be weak in small groups of inflammatory cells around the blood vessels in the substantia grisea and alba (Figure $5 \mathrm{C}$; TNF-a immunostaining, Bar: $100 \mu \mathrm{m})$.

The group I showed negative Bax immunoreaction in the bipolar and multipolar neurons and glial cells (Figure 6A; Bax immunostaining, Bar: $100 \mu \mathrm{m})$. In the group II, positive Bax expression and apoptotic changes were observed in the glial cells and bipolar and some multipolar neurons in the substantia grisea (Figure 6B; Bax immunostaining, Bar: 100 $\mu \mathrm{m})$. In the group III, positive Bax expression was found in

Table I: MDA, MPO, and GSH Values of Experimental Groups and Their Comparisons

\section{Groups}

\begin{tabular}{|c|c|c|c|c|c|c|c|c|c|c|}
\hline & \multicolumn{3}{|c|}{ Control } & \multicolumn{3}{|c|}{ Spinal Cord Injury } & \multicolumn{3}{|c|}{$\begin{array}{c}\text { Spinal Cord Injury + } \\
\text { Amantadine }\end{array}$} & \multirow[t]{2}{*}{$\mathbf{p}$} \\
\hline & $\mathbf{n}$ & Mean & SD & $\mathbf{n}$ & Mean & SD & $\mathbf{n}$ & Mean & SD & \\
\hline MDA (nmol/g) & 10 & 33.29 & 3.30 & 10 & 54.63 & 4.52 & 10 & 38.75 & 2.54 & $<0.001^{*}$ \\
\hline MPO (U/g) & 10 & 4.88 & 0.65 & 10 & 7.54 & 0.66 & 10 & 5.30 & 0.62 & $<0.001^{*}$ \\
\hline
\end{tabular}

${ }^{*} p<0.05$ considered as significant; One-Way ANOVA test results. GSH: Glutathione, MDA: Malondialdehyde, MPO: Myeloperoxidase, SD: Standard deviation, ANOVA: Analysis of variance. 

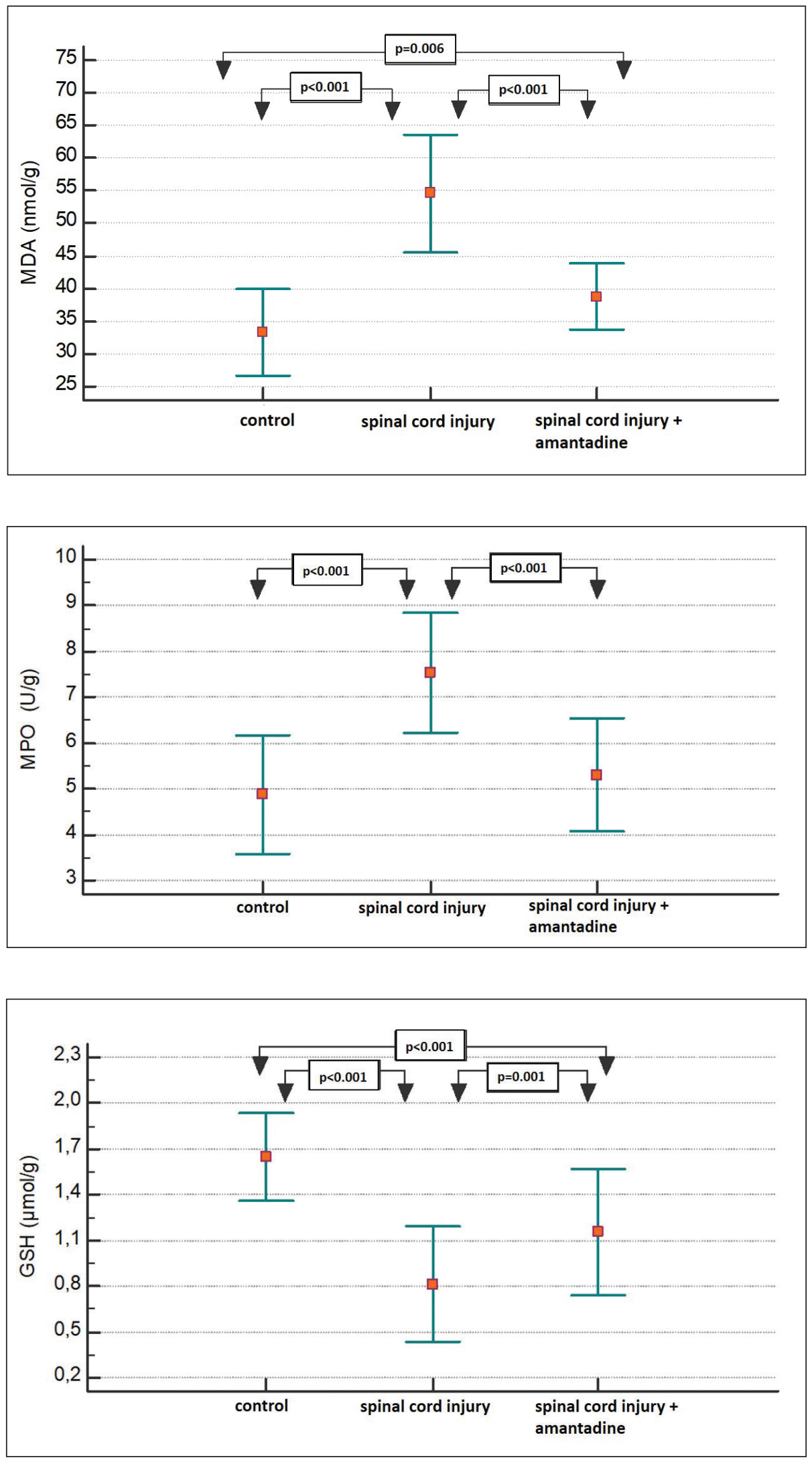

Figure 1: Graphical illustration of MDA levels in all groups.

Figure 2: Graphical illustration of MPO levels in all groups.

Figure 3: Graphical illustration of GSH levels in all groups. 
the substantia grisea layer, particularly in the membrane of some bipolar neurons and glial cells, whereas neuron and glial cells showed negative Bax expression (Figure 6C; Bax immunostaining, Bar: $100 \mu \mathrm{m})$.

On immunohistochemical examination of the group I, positive VEGF expression was observed in small vascular endothelial cells, bipolar and multipolar neurons, and the anterior horn of the spinal cord (Figure 7A; VEGF immunostaining, Bar: 100 $\mu \mathrm{m})$. The group II showed increased VEGF expression in the degenerative neuronal processes, inflammatory cells, and vascular endothelial cells in spinal gray and white matter layers (Figure 7B; VEGF immunostaining, Bar: $100 \mu \mathrm{m}$ ). In the group III, positive VEGF expression was observed in the vascular endothelium, whereas weak VEGF expression was observed in some bipolar and multipolar neurons and glial cells in the substantia grisea layer (Figure 7C; VEGF immunostaining, Bar: $100 \mu \mathrm{m})$.

\section{DISCUSSION}

$\mathrm{SCl}$ is defined as temporary or permanent impairment of spinal cord functions caused by trauma. The primary trauma induces mechanical compression, bleeding, and electrolyte disturbances resulting in irreversible nerve injury. The secondary damage that is caused by edema, hemorrhage, inflammation, lipid peroxidation, energy metabolism system disorders, ischemia, and oxidative stress results in reversible
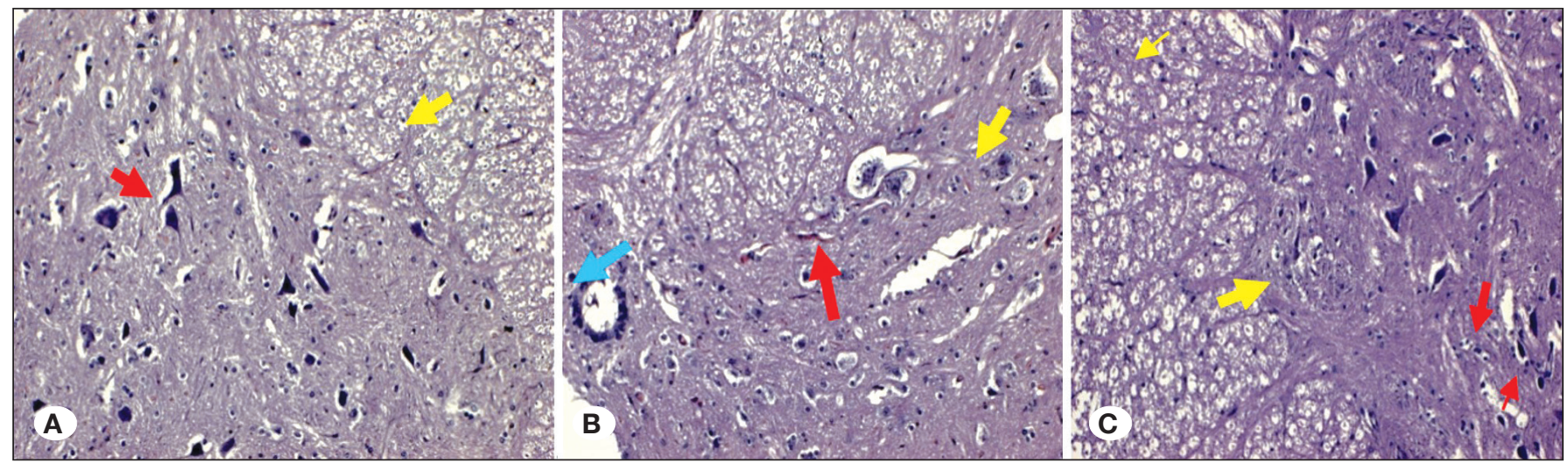

Figure 4: Hematoxylin-eosin stain of spinal cord. Footnote: In the spinal cord sections of the control group, the nuclei of bipolar and multipolar-like neurons in the gray matter layer (red arrow) were rich in chromatin and the nerve extensions were distributed in parallel. The glial cells with oval nuclei and their axonal and dendritic process in the white matter were elongated through the periphery of the synaptic structures (yellow arrow) (A); (Hematoxylin-Eosin stain original magnification X40). In the SCI group, degeneration and apoptotic change in ependymal cells (blue arrow), mononuclear cell infiltration in the substantia grisea layer (yellow arrow), dilatation in the blood vessels and hemorrhage (red arrow) were observed (B); (Hematoxylin-Eosin stain, original magnification X40).In the histopathological examination of the groups treated with $\mathrm{SCI}+$ Amantadine, a small number of inflammatory cells were observed in the gray and white matter (yellow arrow), Mildly degenereated multi-polar and bipolar cells and a small number of glia cells with pyknotic nuclei were seen (red arrow). Synaptic extensions were found to be parallel and prominent (C); (Hematoxylin-Eosin stain, original magnification X40).
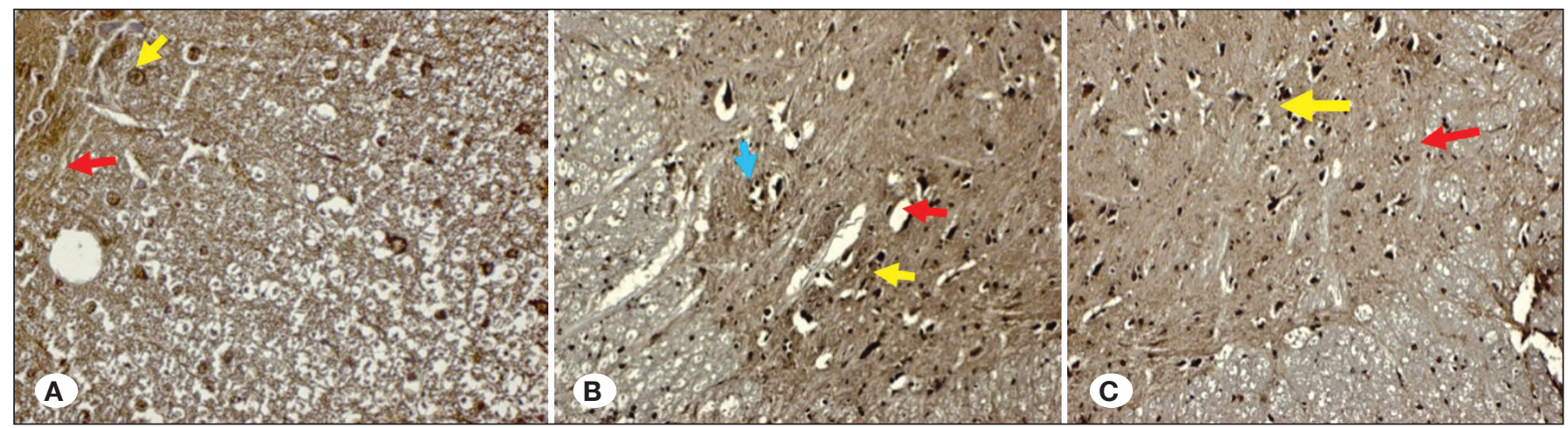

Figure 5: TNF- $\alpha$ immunostaining of spinal cord. Footnote: In the control group, TNF- $\alpha$ reaction was observed in the glia cells and unipolar neurons in the substantia grisea layer (yellow arrow), while it was weak in bipolar and multipolar neurons (red arrow) and synaptic areas (A); (TNF- $\alpha$ immunostaining, original magnification X40). In the trauma group, TNF- $\alpha$ expression was significant in glial macrophages (yellow arrow), dilated vascular endothelial cells (red arrow), Bipolar and multipolar neurons and in inflammatory cells around small blood vessels (blue arrow) (B); (TNF- $\alpha$ immunostaining, original magnification X40). Trauma + Amantadine group; Glial cells and some bipolar and multipolar neurons showed TNF- $\alpha$ expression (yellow arrow), whereas TNF- $\alpha$ was found to be weak in small groups of inflammatory cells around blood vessels in the substantia grisea and alba (red arrow) (C); (TNF- $\alpha$ immunostaining, original magnification X40). 
nerve injury (20). SCI pathophysiology involves both primary and secondary injuries. Lipid peroxidation is one of the significant pathological mechanisms involved in secondary damage after $\mathrm{SCl}$. Another critical factor in the secondary injury mechanism is $\mathrm{Ca}^{2+}$ ions. Both primary and secondary injuries result in increased release of glutamate, sustained activation of glutamate receptors, and increased accumulation of $\mathrm{Ca}^{2+}$. Glutamate exerts these toxic effects through several receptors, including NMDA receptors (10).

The $\mathrm{Ca}^{2+}$ influx plays an essential role in the pathogenesis of neural injury following trauma or ischemia (2). Happel et al. showed that in contused spinal cords the calcium content in the total tissue increases with time (14). Banik et al. reported that perfusion of high $\mathrm{Ca}^{2+}$ concentrations into the spinal cord causes biochemical and histopathological changes, which are similar to those after trauma (3). Therefore, therapeutic approaches that decrease oxidative stress may be potentially beneficial in several neurological diseases (6). Notably, corticosteroids, lazaroids, gangliosides, calcium channel blockers, free radical scavengers, magnesium, sodium channel blockers, cyclosporin A, opioid receptor antagonists, NMDA receptor antagonists, and thyrotropin-releasing hormone have been reported to be promising in experimental $\mathrm{SCl}$ models $(19,28)$. NMDA and non-NMDA receptor antagonists have demonstrated neuroprotective properties both in vitro and in vivo; however, their clinical use is limited because they have major adverse effects (11). We investigated the effect of amantadine because it is an NMDA glutamate receptor antagonist because its use in $\mathrm{SCl}$ has not yet been reported.
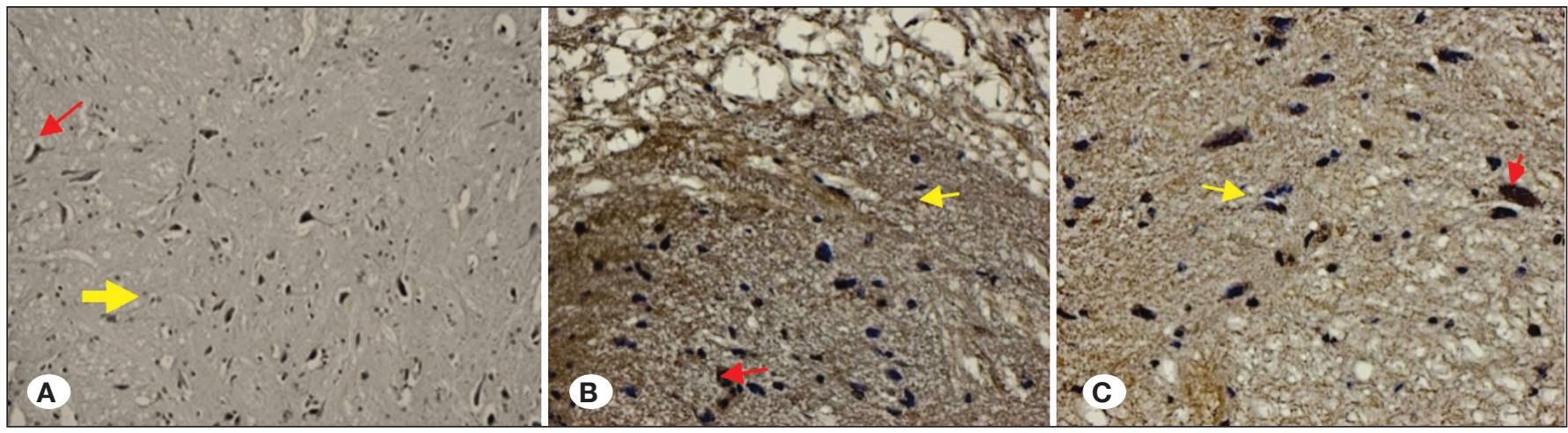

Figure 6: Bax immunostaining of spinal cord Footnote: In the control group of Bax expression, negative Bax immunoreaction was seen in the bipolar and multipolar neurons (red arrow) and the glial cells (yellow arrow), (A); (Bax immunostaining, original magnification X40). $\mathrm{SCl}$ group; in the substantia grisea apoptotic changes were observed in the glia cells (yellow arrow), bipolar and some multipolar neurons with positive Bax expression (red arrow) (B); (Bax immunostaining, original magnification X40). In SCI + Amantadine treated group: Bax expression was found to be positive in the substantia grisea layer especially in the membrane of some bipolar neurons (red arrow) (and glia cells, whereas Bax expression of neuron and glia cells was negative (yellow arrow), (C); (Bax immunostaining, original magnification X40).
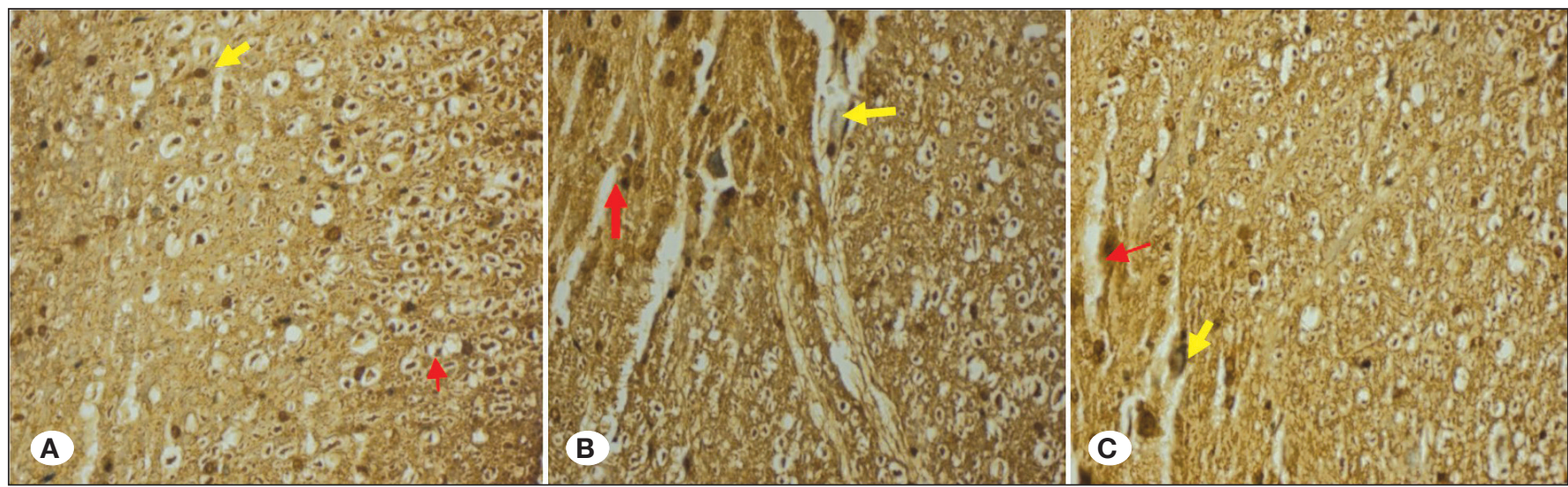

Figure 7: VEGF immunostaining of spinal cord Footnote: Immunohistochemical examination of the control group showed positive expression of VEGF in small vascular endothelial cells (red arrow), bipolar and multipolar neurons and anterior horn of the spinal cord (yellow arrow) (A); (VEGF immunostaining, original magnification X40). An increase in VEGF expression was observed in the processes of degenerative neurons, inflammatory cells (red arrow), vascular endothelial cells of spinal gray and white matter layers due to lesion injury (yellow arrow) (B); (VEGF immunostaining, Bar: $100 \mu \mathrm{m})$. VEGF expression in the vascular endothelium (red arrow), was positive in the SCI + Amantadine-treated group. However, weak VEGF expression was observed in some bipolar and multipolar neurons (yellow arrow) and glial cells in the substantia grisea layer (C); (VEGF immunostaining, original magnification X40). 
Amantadine facilitates dopamine release, delays presynaptic dopamine reuptake and absorption, increases the number of postsynaptic dopamine receptors, and inhibits microglial activation and neuroinflammation $(18,21,24,31)$. Furthermore, it is used to treat the psychiatric symptoms of Parkinson's disease (30). However, it has been proven to be beneficial in multiple sclerosis fatigue, major depressive disorder, traumatic brain injury, and refractory electrical status epilepticus (32).

Biological systems are protected against oxidative damage by antioxidant enzymes such as superoxide dismutase, catalase, GSH peroxidase, MDA, and a combination of other antioxidants (18). GSH is an antioxidant that protects cells from free radicals (11). MDA, which is formed during the breakdown of polyunsaturated fatty acids, functions as an essential and reliable index for determining the extent of peroxidation (25). Emmez et al. demonstrated that gabapentin administration decreased tissue MDA levels in the early phase of experimental SCI (10). In our study, the control group showed increased MDA (Figure 1) and MPO levels (Figure 2) but decreased GSH levels (Figure 3). In contrast, the $\mathrm{SCl}+$ amantadine-treated group showed decreased MDA and MPO levels.

In our study, degeneration and apoptotic changes in ependymal cells, mononuclear cell infiltration in the substantia grisea layer, dilation of the blood vessels, and hemorrhage were observed after SCl. Pyknotic changes were observed in multipolar and bipolar nerve cells and glial cells (Figure 4B). On histopathological examination of the $\mathrm{SCl}+$ amantadinetreated group, few inflammatory cells were observed in the gray and white matter, whereas mild degeneration was evident in the multipolar and bipolar cells and a few glial cells with pyknotic nuclei. Furthermore, synaptic extensions were found to be parallel and prominent (Figure 4C).

TNF-a is a critical proinflammatory cytokine. TNF- $a$ is an acute-phase protein that initiates a cascade of cytokines and increases vascular permeability, thereby recruiting macrophage and neutrophils to the site of infection (12). After $\mathrm{SCl}$, the TNF-a level becomes elevated in the spinal cord, approaching a peak within $1 \mathrm{~h}$ after the initial trauma (8). Baran et al. reported positive TNF-a expression in some bipolar and glial cells following $\mathrm{SCI}$, and it was more prominent in some nerve endings (5). In our study, the oxidative stress after $\mathrm{SCl}$ resulted in the activation of nerve cells and glial cells and caused the release of inflammatory cytokines and TNF-a (Figure 5B).

After $\mathrm{SCl}$, inflammation and vascular structure of the spinal cord play a crucial role in the improvement of apoptotic changes in neurons and glial cells. When apoptosis of neurons and glial cells is counteracted after trauma, the loss of nerve tissue can be substantially decreased, and SCI may improve. The secondary lesion caused by $\mathrm{SCl}$ can damage spinal neurons and trigger apoptotic cascades. Bcl-2 family proteins have been shown to modulate cellular apoptosis. Under normal circumstances, Bcl-2 itself functions as an anti-apoptotic protein, whereas another member of the Bax family functions as a pro-apoptotic molecule (13). Our study provided evidence regarding decreased $\mathrm{Bcl}-2$ and increased Bax protein levels in the spinal cord tissues following SCI.

In this study, Bax expression was increased in neuron and glial cells after SCl (Figure 6B). In the SCl + amantadine-treated group, Bax was expressed in a few glial cells and membranes of some bipolar neurons (Figure 6C). However, amantadine is considered to prevent an apoptotic change in the cell membrane during the pro-apoptotic period.

VEGF expression, angiogenesis, and vascularization are essential contributors after SCI. VEGF is considered to be a crucial neurotrophic for the continuity of spinal cord neurons and endothelial cells. Herrera et aldemonstrated that VEGF is typically expressed in neurons and astrocytes (15). They stated that the neurons at the site of spinal cord injury were significantly lost a day after injury and could add to a general reduction in VEGF. In our study, VEGF expression was increased in the degenerative neuronal processes, inflammatory cells, and vascular endothelial cells in gray and white matter layers after SCI (Figure 7B). VEGF expression was observed in the vascular endothelium of rats in the $\mathrm{SCl}+$ amantadine-treated group. However, weak VEGF expression was observed in some bipolar and multipolar neurons and glial cells of the substantia grisea layer (Figure 7C). Therefore, amantadine induces endothelial development and angiogenesis.

Wang et al. reported that amantadine treatment is a potential neuroprotective treatment after traumatic brain injury and may decrease the associated cognitive dysfunction (31). Amantadine reportedly causes apoptosis with post-traumatic NMDA receptor inhibition, which can inhibit the excessive stimulation of glutaminergic pathways and calcium flow $(26,29)$. Memantine, an NMDA antagonist, is effective in preventing necrosis and apoptosis after $\mathrm{SCl}$ (1). Memantine has been shown to influence inflammation and hormonal status and exhibit anti-inflammatory and neurotrophic effects by downregulating brain cytokines. In our study, we demonstrated that amantadine inhibits oxidative stress and exerts a neuroprotective effect after SCl.

After traumatic $\mathrm{SCl}$ in rats, apoptosis induced by increased TNF-a production results in increased Bax expression. This condition is closely associated with angiogenesis induced by inflammatory cytokines. Inflammatory cytokines have been shown to facilitate angiogenesis in CNS injuries.

\section{CONCLUSION}

A NMDA receptor antagonist, amantadine, may have neuroprotective effect on $\mathrm{SCl}$ by inducing angiogenesis, affecting inflammation and apoptosis. It also inhibits oxidative stress and the signaling pathways after $\mathrm{SCl}$. More experimental studies are needed to elucidate these effects in animals and clinical studies on the application of this agent in patients with $\mathrm{SCl}$.

\section{ACKNOWLEDGEMENT}

We thank Engin Deveci from the Department of Histology and Embryology, Faculty of Medicine, Dicle University, 
Dogan G. and Karaca O: Amantadine and Spinal Cord Injury

Diyarbakır for assistance with histological evaluation. In addition, we thank Yasin Kenesari from the Department of Medical Biochemistry, Sungurlu State Hospital, Corum for his assistance in biochemical evaluations. Finally, we thank Emre Demir from the Department of Biostatistics, Hitit University, Corum for statistical analysis.

\section{REFERENCES}

1. Aydoseli A, Can H, Aras Y, Sabanci PA, Akcakaya MO, Unal OF: Memantine and Q-VD-OPh treatments in experimental spinal cord injury: Combined inhibition of necrosis and apoptosis. Turk Neurosurg 26(5):783-789, 2016

2. Azbill RD, Mu X, Bruce-Keller AJ, Mattson MP, Springer JE: Impaired mitochondrial function, oxidative stress and altered antioxidant enzyme activities following traumatic spinal cord injury. Brain Research 765(2):283-290, 1997

3. Banik NL, Hogan EL, Whetstine LJ, Balentine JD: Changes in myelin and axonal proteins in Cacl2-induced myelopathy in rat spinal cord. Cent Nerv Syst Trauma 1:131-137, 1984

4. Baptiste DC, Fehlings MG: Pharmacological approaches to repair the injured spinal cord. Journal of Neurotrauma 23(3-4): 318-334, 2006

5. Baran O, Cicekci E, Donder A, Atic R, Deveci E, Tuncer MC: Protective effects of melatonin on spinal cord injury. Int $\mathrm{J}$ Morphol 36(2):488-492, 2018

6. Chronidou F, Apostolakis E, Papapostolou I, Grintzalis K, Georgiou, CD, Koletsis EN, Dougenis D: Beneficial effect of the oxygen free radical scavenger amifostine (WR-2721) on spinal cord ischemia/reperfusion injury in rabbits. Journal of Cardiothoracic Surgery 4(1):50, 2009

7. del Rayo Garrido M, Silva-García R, García E, Martiñón $\mathrm{S}$, Morales $\mathrm{M}$, Mestre $\mathrm{H}$, Ibarra A: Therapeutic window for combination therapy of A91 peptide and glutathione allows delayed treatment after spinal cord injury. Basic \& Clinical Pharmacology \& Toxicology 112(5):314-318, 2013

8. Dinomais M, Stana L, Egon G, Richard I, Menei P: Significant recovery of motor function in a patient with complete T7 paraplegia receiving etanercept. J Rehabil Med 41(4):286288, 2009

9. Dumont RJ, Okonkwo DO, Verma S, Hurlbert RJ, Boulos PT, Ellegala DB, Dumont AS: Acute spinal cord injury, part I: Pathophysiologic mechanisms. Clinical Neuropharmacology 24(5):254-264, 2001

10. Emmez H, Borcek AO, Kaymaz M, Kaymaz F, Durdag E, Civi S, Gulbahar O, Aykol S, Pasaoglu A: Neuroprotective effects of gabapentin in experimental spinal cord injury. World Neurosurg 73(6):729-734, 2010

11. Emmez H, Yildirim Z, Kale A, Tonge M, Durdag E, Borcek AO, Baykaner MK: Anti-apoptotic and neuroprotective effects of alpha-lipoic acid on spinal cord ischemia-reperfusion injury in rabbits. Acta Neurochir 152:1591-601, 2010

12. Esposito E, Cuzzocrea S: TNF-alpha as a therapeutic target in inflammatory diseases, ischemia-reperfusion injury and trauma. Curr Med Chem 16(24):3152-3167, 2009
13. Fan L, Wang K, Cheng B: Effects of buyang huanwu decoction on apoptosis of nervous cells and expressions of Bcl-2 and bax in the spinal cord of ischemia-reperfusion injury in rabbits. J Tradit Chin Med 26(2):153-156, 2006

14. Happel RD, Smith KP, Banik NL, Powers JM, Hogan EL, Balentine JD: $\mathrm{Ca}^{2+}-$ accumulation in experimental spinal cord tauma. Brain Res 211:476-479, 1981

15. Herrera JJ, Nesic O, Narayana PA: Reduced vascular endothelial growth factor expression in contusive spinal cord injury. J Neurotrauma 26(7):995-1003, 2009

16. Hillegass LM, Hillegass LM, Griswold DE, Brickson B, Albrightson-Winslow C: Assessment of myeloperoxidase activity in whole rat kidney. J Pharmacol Methods 24(4):285295, 1990

17. Jiang ZS, Pu ZC, Hao ZH: Carvacrol protects against spinal cord injury in rats via suppressing oxidative stress and the endothelial nitric oxide synthase pathway. Molecular Medicine Reports 12(4): 5349-5354, 2015

18. Kale A, Borcek AO, Emmez H, Yildirim Z, Durdag E, Lortlar $\mathrm{N}$, Kilic N: Neuroprotective effects of gabapentin on spinal cord ischemia-reperfusion injury in rabbits. J Neurosurg Spine 15(3):228-237, 2011

19. Kochhar A, Zivin JA, Lyden PD, Mazzarella V: Glutamate antagonist therapy reduces neurologic deficits produced by focal central nervous system ischemia. Arch Neurol 45:148153, 1988

20. Kotipatruni RR, Dasari VR, Veeravalli KK, Dinh DH, Fassett D, Rao JS: p53-and Bax-mediated apoptosis in injured rat spinal cord. Neurochemical research 36(11): 2063, 2011

21. Kwon BK, Okon E, Hillyer J, Mann C, Baptiste D, Weaver LC, Tetzlaff W: A systematic review of non-invasive pharmacologic neuroprotective treatments for acute spinal cord injury. J Neurotrauma 28(8):1545-1588, 2011

22. Kwon BK, Tetzlaff W, Grauer JN, Beiner J, Vaccaro AR: Pathophysiology and pharmacologic treatment of acute spinal cord injury. The Spine Journal 4(4):451-464, 2004

23. Moonen G, Satkunendrarajah K, Wilcox JT, Badner A, Mothe A, Foltz W, Fehlings MG, Tator $\mathrm{CH}$ : A new acute impactcompression lumbar spinal cord injury model in the rodent. Journal of Neurotrauma 33(3):278-289, 2016

24. Pristupa ZB, McConkey F, Liu F, Man HY, Lee FJ, Wang YT, Niznik HB: Protein kinase-mediated bidirectional trafficking and functional regulation of the human dopamine transporter. Synapse 30(1):79-87, 1998

25. Qian H, Liu D: The time course of malondialdehyde production following impact injury to rat spinal cord as measured by microdialysis and high pressure liquid chromatography. Neurochem Res 22:1231-1236, 1997

26. Qin ZH, Chen RW, Wang Y, Nakai M, Chuang DM, Chase TN: Nuclear factor kappaB nuclear translocation upregulates c-Myc and p53 expression during NMDA receptor-mediated apoptosis in rat striatum. J Neurosci 19(10):4023-4033, 1999

27. Rivlin AS, Tator $\mathrm{CH}$ : Effect of duration of acute spinal cord compression in a new acute cord injury model in rat. Surg Neurol 9:39-43, 1978 
28. Rokkas CK, Rokkas CK, Helfrich Jr LR, Lobner DC, Choi DW, Kouchoukos NT: Dextrorphan inhibits the release of excitatory amino acids during spinal cord ischemia. Ann Thorac Surg 58: 312-319, 1994

29. Shacka JJ, Roth KA: Regulation of neuronal cell death and neurodegeneration by members of the Bcl-2 family: Therapeutic implications. Curr Drug Targets CNS Neurol Disord 4(1):25-39, 2005
30. Vanle B, Olcott W, Jimenez J, Bashmi L, Danovitch I, Ishak WW: NMDA antagonists for treating the non-motor symptoms in Parkinson's disease. Translational Psychiatry 8(1):117, 2018

31. Wang T, Huang XJ, Van KC, Went GT, Nguyen JT, Lyeth BG: Amantadine improves cognitive outcome and increases neuronal survival after fluid percussion traumatic brain injury in rats. Journal of Neurotrauma 31(4):370-377, 2014

32. Wilson RB, Eliyan Y, Sankar R, Hussain SA: Amantadine: A new treatment for refractory electrical status epilepticus in sleep. Epilepsy \& Behavior 84:74-78, 2018 